\title{
Phylogenetic relationships of Gordonia Ellis (Theaceae) species endemic to Sri Lanka
}

\author{
D.M.D. Yakandawala and L.A.A.H. Gunathilake \\ Department of Botany, Faculty of Science, University of Peradeniya, Peradeniya.
}

\begin{abstract}
A study of the genus Gordonia Ellis was carried out using morphological data to determine the phylogenetic relationships of the four endemic species, Gordonia ceylanica Wight, G. elliptica Gardner, G. speciosa (Gardn.) Choisy, and $G$. dassanayakei Wadhwa et Weerasooriya. Vegetative and reproductive features were studied in detail from live and herbarium specimens in order to select characters and character states. The phylogenetic analysis was performed using PAUP* computer soft ware. The present analysis using 77 morphological characters recovered a strongly supported monophyletic genus with the endemic Gordonia species. Even though most of the past taxonomic treatments recognized G. ceylanica Wight and G. elliptica Gardner as two distinct species, both species did not receive any support as being monophyletic. G. speciosa (Gardn.) Choisy and G. dassanayakei Wadhwa et Weerasooriya were recovered as monophyletic groups. The study revealed several confusing character combinations that overlap among these species, especially between $G$. elliptica and G. ceylanica questioning their species limits. Therefore, this study emphasizes the necessity of carrying out further studies on species limits of Gordonia with more informative characters such as molecular data.
\end{abstract}

Keywords: Cladistics, Gordonia Ellis, monophyly, morphological data, Sri Lanka

\section{INTRODUCTION}

Family Theaceae harbours approximately 22 genera and about 610 species in the tropical and warm temperate areas of the world ${ }^{1}$. In Sri Lanka, the family is represented by five genera and 12 species, where the well-known tea plant Camellia sinensis (L.) Kuntze is also a member. The genus Gordonia is not endemic to Sri Lanka and is distributed in South East Asia and America. About 40 species are found from India, Sri Lanka, Burma, Thailand, Indo-China, South China, Taiwan, Malaysia, Philippine Islands and New Guinea. Thirty species are also present in North and South America, and the West Indies. The four species that occurr in Sri Lanka ${ }^{2}$ are endemic to the island and includes G. ceylanica Wight, G. elliptica Gardner, G. speciosa (Gardn.) Choisy, and $G$. dassanayakei Wadhwa et Weerasooriya. Of the four species $G$. ceylanica and $G$. elliptica show a wide distribution when compared with the other two species. Both $G$. speciosa and G. dassanayakei are not common and are confined to a few localities. Apart from these four species, several young plants of $G$. axillaries (KerGawl.) D. Diter. have been reported from the forest adjoining the Hakgala Botanical Garden testifying the naturalization of the species within the country ${ }^{3}$. Further, all four species of Gordonia are confined to the upper montane areas of the country.

Based on recent developments, circumscription of the traditional Theaceae has been changed. Theaceae is classified under the monophyletic order Ericales under the asterid clade ${ }^{4}$. The family as traditionally circumscribed, probably are not monophyletic ${ }^{4,5}$. Based on molecular based cladistic analyses the family is restricted to the genera traditionally placed in Theoideae ${ }^{5-7}$. Further three monophyletic tribes Theeae, Gordonieae (including the genus Gordonia ) and Stewartieae have been identified.

G. ceylanica was first described by Wight in 1840 . Seven years later, in 1847, George Gardner, the then Director of the Royal Botanic Gardens, Peradeniya, described two new species, Carria speciosa from the Ramboda area and G. elliptica from Elephant plains -Nuwara-Eliya district. Carria speciosa was later recognizedasamemberofGordoniain 1855 andwasnamed accordingly as $G$. speciosa $a^{2}$. Thwaites in $1858^{8}$ reduced $G$. elliptica as a variety under $G$. ceylanica; $G$. ceylanica var. elliptica (Gardner) Thw. He also recognized two 
species, i.e. G. ceylanica and $G$. speciosa and included $G$. elliptica under $G$. ceylanica as a variety. During the recent revision of the flora Wadhwa (1996), identifies four species of Gordonia; G. ceylanica, G. speciosa, $G$. elliptica and a newly recognized fourth species $G$. dassanayakei ${ }^{2}$. This species with pink flowers has been named in honour of Prof. M.D. Dassanayake, for his valuable contribution to the plant taxonomy of Sri Lanka.

The presence of large fragrant flowers is a characteristic feature of all Gordonia species. G. ceylanica and G. elliptica both bear white coloured flowers that closely resemble the flowers of $C$. sinensis (tea plant). The shape of their leaves is the character used to distinguish the two species from each other ${ }^{2}$. G. elliptica bear elliptic leaves as the name implies while $G$. ceylanica bear lanceolate leaves. G. speciosa bears the most remarkable bright crimson colored large flowers, which easily distinguishes them from the other 3 species. G. dassanayakei is also distinguished from others through its flowers, which are pink in colour (Figures 1-4).

\section{METHODS AND MATERIALS}

Materials: All recorded locations for the occurrence of Gordonia species together with other possible locations were visited periodically in order to collect plants with

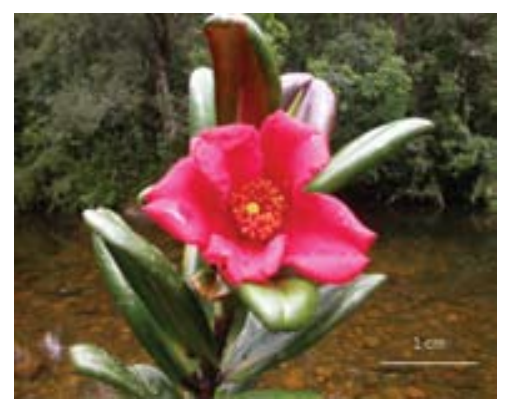

Figure 1: Flower of G. ceylanica Wight

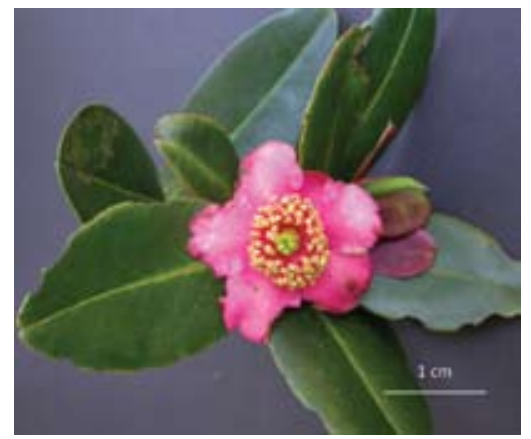

Figure 3: Flower of G. dassanayakei Wadhwa et Weerasooriya vegetative and reproductive parts. In addition, three herbarium specimens for each taxa were also included in the study. Symplocos cochinchinensis (Lour.) S. Moore (Symplocaceae) was selected as the out-group based on a study on the phylogenetic relationships of Theaceae ${ }^{5}$. The details of herbarium materials and voucher specimens are given in Table 1 .

Methods: Vegetative and reproductive features were studied in detail in order to select characters and character states. Flowers were immersed in $70 \%$ alcohol at the time of collection, to preserve characters. All the four floral appendage series were studied separately in each flower, and characters were recorded. Observations were done under the light and stereo microscope as well as under the dissecting microscope. A total of 93 characters were coded into discrete states. Some characters were coded as binary varia- bles and most as multi-state due to extended variation (Table 2). Of the 93 coded characters, only 77 characters were used in the analysis, as the others were not informative.

Data coding and cladistic analysis: The characters were coded into a data matrix using the MacClade 3.04 program $^{9}$. Phylogenetic trees were constructed using the PAUP* 4d55 for Macintosh ${ }^{10}$. For all analyses heuristic searches were performed initially under the unordered and equal weighting criteria of Fitch parsimony ${ }^{11}$ with 500 replicates, random sequence

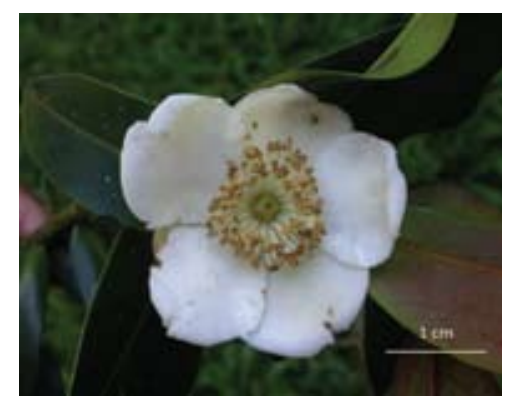

Figure 2: Flower of G. speciosa (Gardn.) Choisy

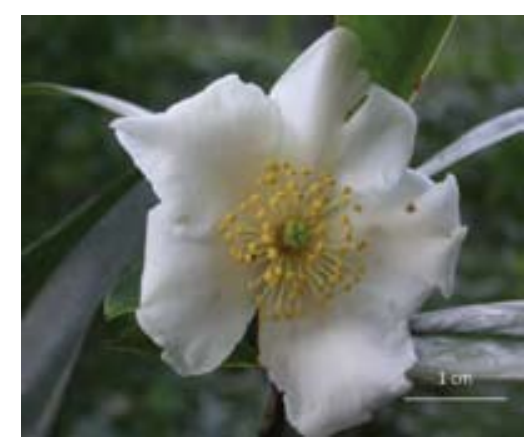

Figure 4: Flower of G. elliptica Gardner 
additions, tree bisection-reconnection (TBR) branch swapping and MULPARS in effect, steepest descent on. Ten trees were held for each step. Strict consensus and $50 \%$ majority rule consensus trees were obtained and branch lengths and tree scores were calculated using ACCTRAN (accelerated transformation optimisation).
The initial trees found with equal (Fitch) weights were used as the basis for successive weighting. Successive weighting was carried based on the Retention Index. Re-weighting was continued until the same length was obtained in two successive rounds. Bootstrap analysis was carried out to evaluate the support for the groupings ${ }^{12}$.

Table 1: Location and the date of collection of the field specimens and the voucher information of the herbarium specimens, National Herbarium, Royal Botanic Gardens, Peradeniya used for the morphological analyses. The herbarium specimens are indicated by the abbreviation PDN in brackets.

\begin{tabular}{|c|c|c|c|}
\hline Species & Voucher/specimen number & Location & Date of collection \\
\hline \multirow[t]{15}{*}{ G. ceylanica Wight } & $\mathrm{GC} 1$ & Knuckels Range (Corbet’s Gap) & 18.02 .2004 \\
\hline & GC2 & Morning Side-Sinharaja & 06.03 .2004 \\
\hline & GC3 & Piduruthalagala & 31.10 .2004 \\
\hline & GC4 & Adisham-Haputhle & 01.02 .2004 \\
\hline & GC5 & Adisham-Haputhale & 03.05 .2005 \\
\hline & GC6 & Thangamali Plains - Haputhale & 03.05 .2005 \\
\hline & GC7 & Hakgala & 03.05 .2005 \\
\hline & GC8 & Mahakoodagala Estate - Kandapola & 03.05.2005 \\
\hline & GC9 & Mahakoodagala Estate & 03.05 .2005 \\
\hline & GC10 & Nuwara-Eliya (Keena Rd.) & 22.05 .2005 \\
\hline & GC11 & Nuwara- Eliya (Keena Rd.) & 22.05 .2005 \\
\hline & Jayasuriya \& Bandaranayake, 1763 & & \\
\hline & $(\mathrm{PDN})$ & Midlands, Matale & 23.07 .1974 \\
\hline & Nowicke \& Jayasuriya 7945 (PDN) & Hakgala, Nuwara Eliya & 30.06 .1973 \\
\hline & Jayasuriya \& Karunaratne 8252 (PDN) & Kandapola-Sita Eliya Forest Reserve & 07.09 .1994 \\
\hline \multirow[t]{8}{*}{ G. elliptica Gardner } & GE1 & Knuckles Range (Corbet’s Gap) & 09.05 .2005 \\
\hline & GE2 & Rattota-Illukkumbura Rd. & 07.05 .2005 \\
\hline & GE3 & Rattota-Illukkumbura Rd. & 07.05 .2005 \\
\hline & GE4 & Thangamali Plains - Haputhale & 03.05 .2005 \\
\hline & Huber,797 (PDN) & Hoolankande Estate, Madulkele & 20.08 .1978 \\
\hline & Kostermans 25066 (PDN) & Knuckles, Madulkele & 12.06 .1973 \\
\hline & Wadhwa, Weerasooriya \& & Rattota-Illukkumbura Road & 23.11 .1994 \\
\hline & Samarasinghe 501 (PDN) & & \\
\hline \multirow[t]{6}{*}{ G. speciosa(Gardn.) Choisy } & GS1 & Fishing Huts - Maskeliya & 15.05 .2004 \\
\hline & GS2 & Adams Peak trail via. Rathnapura & 13.02 .2005 \\
\hline & GS3 & Adams Peak trail via. Kuruwita & 13.02 .2005 \\
\hline & $\begin{array}{l}\text { Jayasuriya, Balasubramaniam, Greller, } \\
\text { S. \& N. Gunatilleke } 2835 \text { (PDN) }\end{array}$ & Peak Wilderness, Meriyakota & 16.08.1984 \\
\hline & Balakrishnan 592 (PDN) & Moray Estate, Maskeliya & 03.02 .1971 \\
\hline & $\begin{array}{l}\text { Jayasuriya \& Sumithraarachchi } 1563 \\
(\mathrm{PDN})\end{array}$ & $\begin{array}{l}\text { Adams Peak Wilderness, Moray Estate } \\
\text { Estate }\end{array}$ & 27.03 .1974 \\
\hline \multirow[t]{6}{*}{$\begin{array}{l}\text { G. dassanayakei Wadhwa et } \\
\text { Weerasooriya }\end{array}$} & GD1 & Thangamali Plains - Haputhale & 03.02 .2005 \\
\hline & GD2 & Thangamali Plains & 03.02 .2005 \\
\hline & GD3 & Thangamali Plains & 03.02 .2005 \\
\hline & Huber $685(\mathrm{PDN})$ & West slopes of Knuckles - Bambarella & 22.11 .1977 \\
\hline & Wadhwa \&Weerasooriya 380 (PDN) & Namunukula Hill forest & 05.12 .1992 \\
\hline & Wadhwa \&Weerasooriya 126 (PDN) & Namunukula Hill forest & 16.10.1992 \\
\hline
\end{tabular}


Table: 2: Qualitative and quantitative characters assessed for the phylogenetic analyses

\begin{tabular}{cl}
\hline Character number & \multicolumn{1}{c}{ Description } \\
\hline Vegetative characters & \\
1. & colour of the dry bark \\
2. & colour of the live bark \\
3. & fissured bark \\
4. & vertical ridges \\
5. & branchlets pilose \\
6. & leaves crowed at extremities \\
7. & leaf arrangement \\
8. & leaf shape \\
9. & leaf tapering \\
10. & texture of the leaf \\
11. & leaf margin \\
12. & leaf apex \\
13. & glandular point \\
14. & mid-rib channeled on the upper surface \\
15. & hairs along the mid-rib \\
16. & veins obsolete \\
17. & hairs on the upper surface of the lamina \\
18. & hairs on the lower surface of the lamina \\
19. & coloured flush \\
20. & hairs present on the young leaves \\
21. & hairs present on the mid-rib of the flush \\
22. & hairs on the leaves unicellular unbranched hairs \\
23. & nature of the petiole \\
24. & length of the petiole \\
\hline
\end{tabular}

Floral characters

$\begin{array}{ll}25 . & \text { axillary flowers } \\ 26 . & \text { solitary flowers } \\ 27 . & \text { flower diametre } \\ 28 . & \text { flower pedicle } \\ 29 . & \text { average length of the pedicle } \\ 30 . & \text { flower colour } \\ 31 . & \text { sepal number } \\ 32 . & \text { orbicular sepals } \\ 33 . & \text { texture } \\ 34 . & \text { persistent sepals } \\ 35 . & \text { concave sepals } \\ 36 . & \text { two large inner sepals } \\ 37 . & \text { sepal arrangement } \\ 38 . & \text { petal shape } \\ 39 . & \text { petal number } \\ 40 . & \text { petal arrangement } \\ 41 . & \text { pubescent present on the upper surface } \\ 43 . & \text { pubescent present on the lower surface } \\ 44 . & \text { connate at the base } \\ 45 . & \text { Stamens numerous }\end{array}$




\begin{tabular}{ll} 
Character number & \multicolumn{1}{c}{ Description } \\
\hline 46. & Stamens clustered \\
47. & Stamens in 3 whorls \\
48. & stamens free \\
49. & stamens adnate to the base of the petals \\
50. & stout filaments \\
51. & length of the filaments \\
52. & pubescent on the filaments \\
53. & shape of the anthers \\
54. & versatile anthers \\
55. & connective broad \\
56. & ovary position \\
57. & no. of locules \\
58. & hairs on the ovary \\
59. & unicellular, unbranched hairs \\
60. & ovule arrangement \\
61. & arrangement of ovules in two rows \\
62. & style length \\
63. & stout style \\
64. & fused style \\
65. & hairs on the style \\
66. & no. of lobes of the stigma \\
67. & capsule texture \\
68. & capsule shape \\
69. & no. of angles in the capsule \\
70. & persistent sepals \\
71. & hairs on the fruit \\
72. & unicellular, unbranched hairs \\
73. & size of the fruit \\
74. & fruit apiculate \\
75. & dehiscence \\
76. & winged seeds \\
77. &
\end{tabular}

\section{RESULTS}

Heuristic search under the Fitch criterion yielded 42 most parsimonious trees (MPTs) with 220 steps, Consistency Index $(\mathrm{CI})=0.447$ and Retention Index $(\mathrm{RI})=0.686$ (figures not shown). The successive weighting resulted in a single most parsimonious tree with a length of 143.498, CI of 0.321 and RI of 0.910 (Figure 9). The genus is recovered as a monophyletic group with strong support $($ Bootstrap value $=100 \%)$. The four species of Gordonia has not been recovered as monophyletic. Only G. speciosa and G. dassanayakei were recovered as monophyletic groups with $96 \%$ and $73 \%$ bootstrap support respectively. Majority of $G$. ceylanica individuals were recovered as monophyletic but with no support. However, a small monophyletic group of four individuals receives a $60 \%$ bootstrap support. This large group also included an individual of G. elliptica. The other two individuals were scattered, where one occurred as the sister to the large monophyletic clade $G$. dassanayakei and the large clade that includes the majority of G. ceylanica, while the other occurs as the basal most taxa for the genus. Majority of G. elliptica individuals occur as monophyletic clade together with G. speciosa which is nested as a strongly supported group. The rest of the individuals occur as basal taxa for the genus while one occurs within the $G$. ceylanica clade.

\section{DISCUSSION}

The present analyses using 77 morphological characters recovered a strongly supported monophyletic genus with 
the endemic Gordonia species. Although most of the past taxonomic treatments recognized G. ceylanica and G. elliptica as two distinct species, both species did not receive any support as being monophyletic. G. speciosa and $G$. dassanayakei were recovered as monophyletic groups. Even though a majority of $G$. ceylanica is recovered an a monophyletic group, this clade does not receive support. Further an authenticated herbarium specimen of G. elliptica (Huber, 797) is within the clade. It is interesting to note that the scattered individuals of both G. ceylanica (Jayasuriya and Bandaranayake, 1763) and G. elliptica (Huber, 797 and Kostermans, 25066, Wadhwa, Weerasooriya \& Samarasinghe 501) are herbarium specimens that were cited under each of these species as 'examined specimens' during the revision of the family for the Revised Handbook to the Flora of Ceylon². Considering the two taxa, G. elliptica individuals are the most displaced. Several reasons may attribute to this situation. In many circumscriptions, the distinction between the two species are based on few characters; the latest revision employs the leaf shape and the presence of hairs on the young leaves and branches to distinguish $G$. ceylanica from $G$. elliptica and $G$. dassanayakei. However, during the present study, populations of $G$. ceylanica were encountered with glabrous young leaves and branches (specimens collected from Pidurutalagala). During these instances, the leaf shape will be the only character that will distinguish the two species. During the detailed study of morphological characters too it was noted that many characters overlap. Distinguishing between G. elliptica and G. dassanayakei is straight forward with the white flowers; elliptic leaves and the slightly revoluted margin in the lower part of the leaves of the former. Considering the leaf shapes, although shape seems to be consistent for a given species, during coding of data it was apparent that the shapes showed a continuum. Further, the leaf shapes of $G$. elliptica and $G$. dassanayakei were overlapping in many instances, with the only difference being the difference in size. In such a case as this, the flower colour becomes the only parameter that differentiates $G$. elliptica and $G$. dassanayakei. Studying herbarium specimens in detail at the National Herbarium, Royal Botanic Gardens, Peradeniya also had proved this argument. Several specimens that had been identified/ authenticated for species level during the revision of the flora had key characters that were overlapping. The specimen that is identified as $G$. ceylanica, (Weerasooriya, Samarasinghe and Karunaratne, 116) is similar to G.dassanayakei in all aspects except the leaf shape, which is lanceolate. Even the flower colour is indicated as pink. One may argue that this should remain under G.ceylanica since the leaf shape is lanceolate, but then the question arises as to whether the flower colour should not be taken into consideration when assigning a species? Further, G. ceylanica (Kostermans

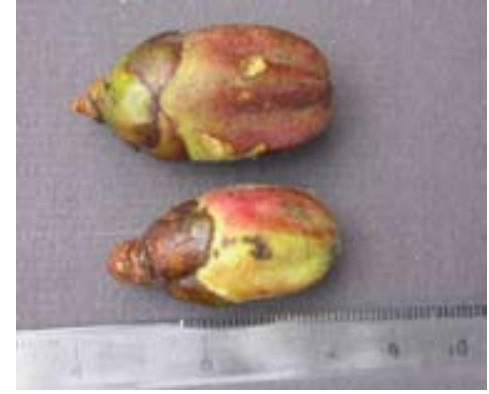

Figure 5: Fruits of G. dassanayakei Wadhwa et Weerasooriya

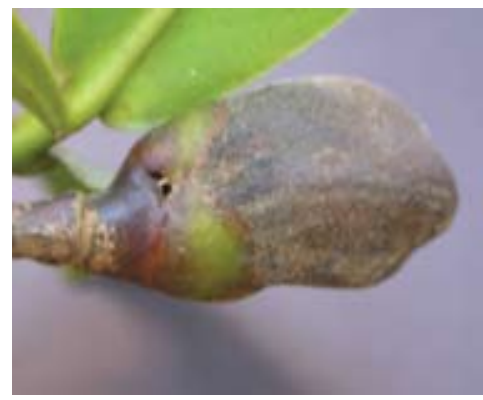

Figure 7: Fruit of G. ceylanica Wight

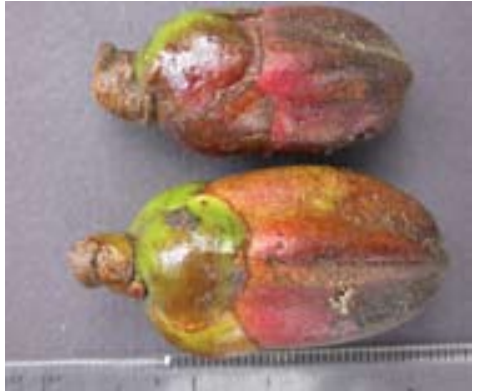

Figure 6: Fruits of $G$. elliptica Gardner

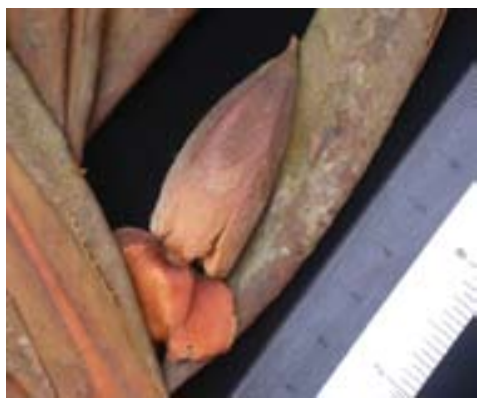

Figure 8: Fruit of G. speciosa (Gardn.) Choisy 


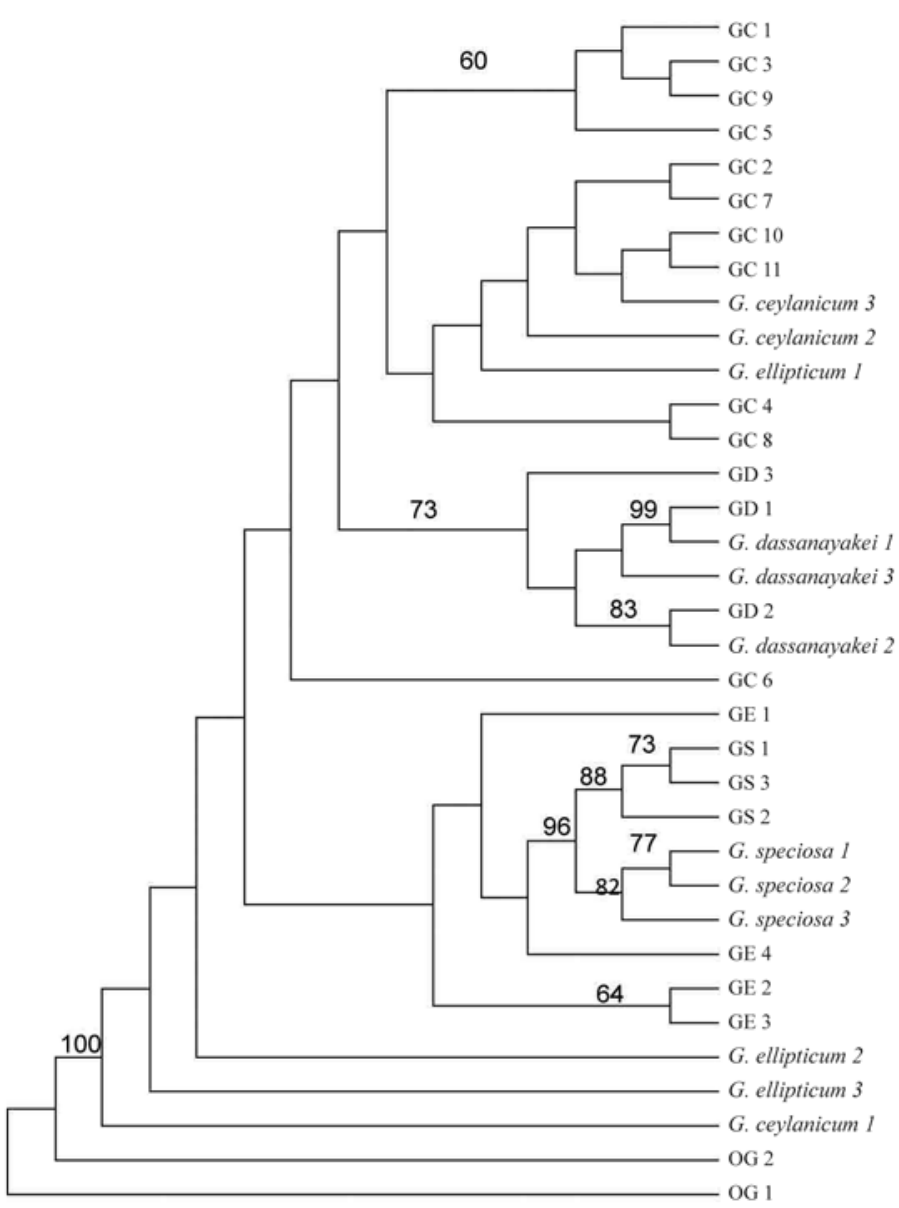

Figure 9: The single most parsimonious tree recovered during the successive weighting of the morphological data. Length $=143.498$, steps, $\mathrm{CI}=0.321$ and $\mathrm{RI}=0.910$. The bootstrap support values are shown above the branches. GC 1-3, GE 1-3, GS 1-3 and GD 1-3 - field collected specimens of G. ceylanica, G. elliptica, G. speciosa and G. dassanayakei respectively while the others are herbarium specimens, where the details are given in Table $1 . \mathrm{OG}$ - out group taxa.

25099) is another specimen with the flower colour indicated as purple. Nooteboom 3413 is identified as $G$. ceylanica but this specimen bearing elliptic leaves shows close resemblance to G. elliptica. Similarly, Waas 1614 is determined as G. elliptica. But it is similar to $G$. ceylanica in all aspects. Even the leaf shape is lanceolate. Therefore, it is evident that the identification of G. elliptica, G. ceylanica and G. dassanayakei does have problems with certain morphological characters. These problems of overlapping characters would have been one reason for not recovering monophyletic groups. Further, these characters which were considered may not have evolutionary significance. $G$. dassanayakei is recovered with moderate support. $G$. dassanayakei together with a majority of $G$. ceylanica contributes to a larger monophyletic group with no support. G. speciosa has received strong support as monophyletic. This group is placed once again within a large monophyletic group together with G. elliptica, where the large clade has not received support.

According to the present study and detailed character analysis, only G. speciosa could be unequivocally placed into a species. G. speciosa had clear-cut, well defined characteristics of its own, while the other three species had characteristics that seemed to overlap with each other. Considering the leaf shapes, G. speciosa leaves had a consistent, unique, characteristic appearance with highly revolute margins and a thick, shiny leaf lamina, which set it apart from the rest. Comparing the fruit shapes (Figures 5-8) it could be seen that the fruits of $G$. speciosa had a unique pyramidal shape, while the fruits of G. elliptica, G. dassanayakei and G. ceylanica all had a similar globose appearance. Comparison of 
flowers of the four species further emphasizes on the above-mentioned argument. Flowers of $G$. speciosa are very large when compared to the flowers of the other three species and are very attractive and conspicuous with a bright crimson colour. But the flowers of the other three species did not vary much from each other. As it can be seen from Figures 1-4, the basic shape of the three flowers other than G. speciosa are the same with $G$. elliptica and $G$. ceylanica being almost identical. $G$. dassanayakei varies only by its colour.

In 1847, Gardner recognized G. elliptica first as a Carria species and next as a Gordonia, but later Thwaites reduced this species to a variety ${ }^{2}$. This was also adopted by Trimen ${ }^{13}$. After hundred and three years, it was only during the revision of the Trimen's Flora that the species was resurrected ${ }^{2}$. The positions of both $G$. elliptica and $G$. ceylanica are not supported during the analysis. Therefore, based on the present study, re-evaluation of the species limits of the Gordonia is suggested as it is the basis of biodiversity conservation and management plans.

\section{CONCLUSION}

The phylogenetic analyses of the endemic Gordonia species using morphological data recovered a strongly supported monophyletic genus. G. speciosa and $G$. dassanayakei are monophyletic whereas $G$. elliptica and G. ceylanica are non-monophyletic.

The study revealed several confusing character combinations that overlap among these species, especially between $G$. elliptica and $G$. ceylanica questioning their species limits. This emphasizes the necessity of carrying out further studies on species limits of Gordonia that are endemic to Sri Lanka.

\section{References}

1. Mabberley D.J. (1997). The plant-book: A portable dictionary of the vascular plants, second edition. pp. 708-
709, Cambridge University Press, Cambridge, UK.

2. Wadhwa B.M. (1996). Theaceae. In: A Revised Handbook to the Flora of Ceylon, Vol. 10. (Eds. M.D. Dassanayake \& W.D. Clayton) pp 386-395,Oxford \& IBH Publishing Co. Pvt. Ltd., New Delhi.

3. Weerasoooriya Aruna (1998). Gordonia - a genus with fascinating endemics in Sri Lanka. Sri Lanka Nature 1 (3): 23-24.

4. Angiosperm Phylogeny Group (APG II). (2003). An update of the Angiosperm Phylogeny Group classification for the orders and families of flowering plants: APG II. Botanical Journal of the Linnaean Society 141: 399-436.

5. Prince L.M. \& Parks C.R. (2001). Phylogenetic relationships of Theaceae inferred from chloroplast DNA sequence data. American Journal of Botany 88(12): 2309-2320.

6. Morton C.M., Kron K.A. \& Chase M.W. (1997). A molecular evaluation of the monophyly of the order Ebenales based upon $r b c L$ sequence data. Systematic Botany 21: 567-586.

7. Morton C.M., Mori S.A., Prance G.T., Karol K.G. \& Chase M.W. (1997). Phylogenetic relationships of the Lecythidaceae: a cladistic analysis using $r b c L$ sequence and morphological data. American Journal of Botany 84:530-549.

8. Thwaites G.H.K. (1858). Enumeratio Plantarum Zeylaniae, William Pamplin, Soho Square, London.

9. Maddison W.P. \& Maddison D.R. (1992). MacClade 3.04: analysis of phylogeny and character evolution, version 3.0.4. Computer Software. Sinauer Associates, Inc. Sunderland, Massachusetts, USA.

10. Swofford D.L. (1998). PAUP* : Phylogenetic analysis using parsimony (and other methods) Beta verstion 4.0. Computer Software, Sinauer Associates, Sunderland, Massachusetts, USA.

11. Fitch W.M. (1971). Towards identifying the course of evolution: minimum change for a specified tree topology. Systematic Zoology 20: 406 -416.

12. Felsenstein J. (1985). Confidence limits on phylogeneies: an approach using the bootstrap. Evolution 39 :783-791.

13. Triman H. (1893). A Handbook to the Flora of Ceylon. Vol 1. pp. 110-112. Dalau \& Co., London. 